\title{
APO: Avoid Pragmatic Overload
}

\author{
Regine Eckardt, University of Göttingen, Germany
}

\section{Change Without MYSTERIES}

Much recent work in historical linguistics, notably historical pragmatics, is focused on the mysterious moment where a new item or construction sees the day of the light. Theoretically speaking, such a situation should have the following characteristics:

(1) There is a speaker who makes an utterance: $u$

$u$ is still part of the old language stage $L_{\text {old }}$

The hearer understands: $u$ '

$u^{\prime}$ is part of the new stage $L_{\text {new }}$

If we really want to capture moments of change, we must assume that the hearer was not already competent in the new language stage $L_{\text {new }}$ before $\mathrm{s} /$ he understood $u$ '. The innovation is constituted by the hearer parsing the utterance and deriving a meaning in a way that differs from what the speaker had in mind with her utterance $u$.

There are several proposals in the literature about how situations of this kind can arise. One very simple scenario really avoids all difficulties by claiming that new language stages typically come about by innovative acts by the speaker. The speaker can decide to use language in innovative ways, and to the extent that the hearer can make sense of an innovative utterance, and adopts the suggested underlying pattern, the hearer confirms and adopts the new language stage. This view is already inherent in traditional work in language history (von der Gabelentz 1891, Paul 1920) and it is moreover extremely plausible, because we can observe innovative utterances on a daily basis. Yet, when we think about the origin of the more routine 
parts of language - aspect forms, particles, tenses - it is unlikely that all these have come about by witty remarks of creative speakers.

According to another scenario, innovations can enter a language because hearers are incompetent, simply misunderstanding the intended linguistic structure of the speaker's utterance. Indeed, we know that an increased rate of potential misunderstandings, for example in large L2 communities, may lead to increased speed in language change but there are interesting cases in the histories of languages where no such driving force would be known.

In recent work, Traugott and Dasher have devised another detailed scenario which illustrates the above type of situation (Traugott and Dasher, 2002). Traugott in fact was the first to point out that pragmatic processes are a driving force in language change (König and Traugott, 1988, Traugott, 1988), and this is explored in her theory of implicature-based language change. An utterance can mean more than its literal meaning (implicatures). Implicated information can turn into lexically denoted information (generalized invited inferences, GIINs). Due to this reinterpretation (by the hearer), items and constructions can change in meaning. Again, the appeal of the analysis lies in the fact that it rests on pragmatic processes that can be witnessed all over the place in contemporary communication. Hence, the GIIN theory of language change adheres to the Uniformitarian Principle.

In the present paper, I want to draw attention to yet another pragmatic factor that can lead to utterance-comprehension mismatches of the type in (1), namely the presuppositions of utterance $u$. A sentence $u$ presupposes further information $\phi$ if $u$ only makes sense at all if $\phi$ is known. Definite noun phrases like 'the king of France' are typical textbook examples. Most sentences that contain the NP 'the king of France' will only make sense-whether they be true or false-if there is such a person in the first place. If a speaker utters a sentence with presupposed information, s/he relies on shared knowledge between speaker and hearer. How can presuppositions give rise to language change? Sometimes, a speaker will utter a sentence $u$ which presupposes information $\phi$ that the hearer actually did not know before. In this case, the hearer will frequently just tacitly adopt $\phi$ as another piece of new information that the speaker seems to believe (or else, the speaker would not have uttered $u$ ). If the hearer feels that $\phi$ is totally unwarranted, s/he can object ('hey, listen, there is no king of France'). In the present paper, I will investigate a further kind of semantic accident that presuppositions can cause, one that, to my knowledge, has not received attention in either semantics/pragmatics or historical linguistics. We find linguistic exchange where an utterance $u$ presupposes information $\phi$ that is "hard to believe" not in the sense that it would be a proposition with clear but dubitable content. Sometimes, presuppositions are "hard to believe" in that it is unclear what the presupposed facts that would license an utterance could look like at all. Hearers (or readers) of such utterances will diagnose that (i) either the speaker believes facts about the world that are unclear and dubious or that (ii) the speaker might have used words or phrases in a sense that were formerly unknown to the hearer. If the hearer pursues hypothesis (ii), s/he may come to interpret the utterance in some innovative way $u$ ' that defines a new language (micro) stage $L_{n e w}$ even though the speaker firmly believed that he/she was making an utterance $u$ in the conservative $L_{\text {old }}$. From the speaker's perspective, all the hearer would have had to do is adopt- 
and-believe some presuppositions (we will use the official term accommodation later). From the hearer's perspective, it was harder to accommodate the presupposed information than to believe that the utterance was really something new. The utterance created too much pragmatic overload. This is the abstract backbone of the proposal.

I will discuss four example cases where I believe that this proposal is better in line with the attested uses at certain phases of semantic change than either one of the accounts that I listed at the beginning. I can not exclude that the real change came about in ways different from those that I will devise here. However, the present proposal is an attempt to make sense of data in phases of change which are hard to reconcile with other analyses of change, notably those listed at the beginning. In the next sections I will introduce the examples and will list the open questions that are posed. I will then offer a more detailed introduction of presuppositions and presupposition accommodation, the core concepts of my proposal. We will then see how change arises from pragmatic overload in each of the examples at stake.

\section{IMPLICATURES ARE NOT ENOUGH}

In this paper, I will be concerned with the following four items. All of them passed at least once from one meaning to a subsequent new meaning, as listed here.
German fast
(1) ,immovably, tight' >
(2) , very much'>
(3) , almost'
English even
(1), flat, smooth' >
(2)
(3) scalar particle
German selbst
(1) intensifying -self > (2), even'
Italian perfino
(1) ,through to the end
(2) ,even'

When looking at these semantic stages, one can not but wonder what kind of absentmindedness or creative impulse would drive a speaker - any speaker - to initiate the respective innovation. Scalar particles notoriously have incensed researchers' interest (for a survey, see e.g. Traugott, 2006). Consider fast $t_{2}$ to fast 3 in German. Who would use a word meaning, very much' to express the concept of approximation? Take even: Who would use a word that means ,exactly' to express the concept of scalar extremity? In the examples below, I try to give a feeling for the distance between old meaning - new meaning. If we were to witness a change scenario, speaker of $L_{\text {old }}$ would have utter the (a) sentence and the hearer would have to understand something like the (b) sentence.

a. speaker: "Tom is very drunk"

b. hearer understands: ,Tom is almost drunk'

a. speaker: "Sally went exactly to the police"

b. hearer understands: ,Sally went even to the police'

It is virtually impossible to conceive of any context / content of utterance where the (a) utterances would give rise to implicatures like those in (b). This is particularly clear for the 
case of fast $_{\text {German }}$. It has been argued that almost $S$ entails not $S$ (Sadock, 1981) while very $S$ certainly does entail $S$. The relevant entailments are summarized in (4).

Tom is very drunk $\rightarrow$ Tom is drunk.
Tom is almost drunk $\rightarrow$ Tom is not drunk.

If (2.b) were an implicature of (2.a), we'd face a case of an utterance with a logically contradicting implicature. This only happens when a speaker flouts the maxim of quality and makes an ironic statement. It would be possible, of course, to use very / fast ${ }_{\text {German }}$ in an ironic statement. Yet, then we'd normally understand that "very much P", ironically, conveys that "not $\mathrm{P}$ at all". For the other three instances of change, it is likewise hard to tell a story how implicatures should give rise to the newer sense.

Yet, speculations are of limited value and instead of debating the possibility or impossibility of certain types of implicatures, we should take a look at usages of the items in question that have been found indicative for imminent or ongoing change by earlier authors. Traugott (2001/2006) offers a detailed discussion of data in the phase of emergence of even in the scalar sense. Among other examples, she offers (5) as an interesting quote around the turning point from ,exactly' to scalar particle.

when I remembre your ffavour and your sadde loffynge delynge to me wardes, ffor south ye make me evene veray glade and joyus in my hart; [...] , when I remember your beauty and sober loving behaviour toward me, truly you make me $<$ even $>$ very glad and joyous in my heart ...'

(1476 Private Letters of John Shillingford, II,7, after Traugott 2001:10)

We will certainly agree with Traugott's diagnosis that (5) does not show a straightforward use of even in the then predominant sense ,exactly, just'. However, it is not a use of the type that one would expect in the light of the GIIN theory either. Specifically, this is not a passage where the speaker literally utters "you make me exactly happy" and thereby implicates "you make me very happy". As the first proposition does not implicate the second even in particular, it can't be a generalized invited implicature, either. Pre-theoretically speaking, (5) simply looks like a mistaken choice of words by the writer, a Thomas Betson to his cousin Katherine Ryche (Traugott 2001:10). Traugott glosses the use as „emphatic“ which is a plausible prose characterization of the passage, but not part of an analysis of the development in terms of generalized invited inferences.

Similar "mistaken" uses can be found for the other three items in (1) at the turn between older and newly emerging additional sense. Given that they don't seem to exemplify implicature, nor irony, nor any other known rhetorical pattern, one might want to know what was going on there. I will elaborate the hypothesis that such examples show instances of pragmatic overload and are reinterpreted by the reader in order to Avoid Pragmatic Overload. In the next section, I will introduce the notion of presuppositions in some more detail before we turn to an illustration of the Avoid Pragmatic Overload reanalysis on basis of our four sample items. 


\section{PRESUPPOSITION IN HISTORICAL LINGUISTICS}

The presuppositions of a sentence $\mathrm{S}$ are those pieces of information that the speaker needs to believe in order to make sense of S: S presupposes $\phi$ if S can only be reasonably be uttered if $\phi$ is assumed to hold true. Notably, presuppositions need to hold independently of whether the content of S is asserted, denied, questioned, modalized etc. (see Geurts, 1999 for a very clear survey of presupposition tests). A presupposition $\phi$ of $\mathrm{S}$ is not entailed by $\mathrm{S}$; negating $\mathrm{S}$, or asking whether $\mathrm{S}$, also requires that the speaker believes that $\phi$. The following sentences illustrate the phenomenon.

(6) My grandmother stopped smoking pot.

(7) My grandmother did not stop smoking pot.

(8) Has your grandmother stopped smoking pot?

Each of (6) to (8) presuppose $\phi=$,My grandmother used to smoke pot.'

Ideally, in actual communication, speaker and hearer share information that is presupposed by the speaker's utterance. For the speaker, the requirement is tantamount to not making senseless contributions. A rational speaker will only assert $\mathrm{S}$ if $\mathrm{s} /$ he believes that the presuppositions of $\mathrm{S}$ hold true. An utterance like the following is incoherent.

$$
\text { \# My grandmother stopped smoking pot and I don't believe that she ever smoked pot. }
$$

For the hearer, matters may be somewhat different. In many cases, the hearer will not have been aware of all pieces of information that are presupposed by the speaker's utterance. Having spotted the presuppositions, however, the hearer will usually assume that the speaker has made a meaningful contribution and adopt the presuppositions as part of shared common knowledge. In technical terms, the hearer will accommodate the presuppositions of the speaker's utterance.

A: Did Granny finally stop smoking pot?

B accommodates: A's grandmother must have been smoking pot.

Stalnaker (2002) offers an explicit modelling of presupposition accommodation in terms of common ground update. Presupposition accommodation is exploited rhetorically, for instance when the speaker wants to convey information without plainly asserting it. When a teacher tells her student „I regret to inform you that you have failed the exam", she actually asserts 'I regret S' and presupposes 'S holds true'. The student will have to accommodate S: 'I failed the exam' in order to make sense of the teacher's assertion 'I regret S'. Hence, the teacher will effectively, but not rhetorically, have informed the student about the failing. Yet, such rhetorical tricks will not play a role in our examples.

Sometimes it may be hard to guess and accommodate the correct presuppositions that the speaker has in mind. In such cases, the hearer can ask back. In (11), the particle also gives rise 
to the presupposition that Tommy knows more persons who wear wonder bras. If Sue does not know who that may be (Tommy himself being an unlikely option), she can ask back.

(11) Tommy: Do you also wear ,wonder bra'?

Sue: Yes, why — who else does?

Finally, the presuppositions of the speaker's utterance may be problematic in that they are in conflict with general knowledge. Assume that someone utters (12) (with the indicated accent, and the additive particle associating with you).

Are you ALSO a mother of Peter Smith?

In (12), also gives rise to the presupposition $\phi=$ 'the speaker knows more mothers of Peter Smith'. Most likely, the hearer would challenge the presupposition („Peter Smith has several mothers?") and reject it. Sometimes, as we will see, such unreasonable presuppositions are less easy to express than in the case at hand. In such cases, hearers are less likely to start debating and instead may just try to make sense of the utterance one way or other. Even in (12), the hearer could decide to adopt an interpretation of the sentence that allows for the accommodation of the presupposition. Specifically, the word mother could be interpreted in a way that allows for people to have several mothers (,interpret mother as one of the women who pamper Peter Smith"). However, the more far-fetched such interpretations get, the more semantic charity is necessary in order to do justice to the presuppositions. This is what I call "the utterance carries a pragmatic overload".

\section{IMPLAUSIBLE PRESUPPOSITIONS}

We will now turn to our list of four items even, fast, perfino, and selbst. It turns out that the items in their older senses likewise give rise to presuppositions, but to more subtle ones than the examples in section 3. We will take a closer look at each case in turn. At the time antedating the emergence of the contemporary senses of these words, we find uses of the word in sentences where presuppositions can not be accommodated because they contradict common world knowledge. Let us say that little pragmatic ,accidents“ happened from time to time. Not all of these accidents necessarily need to lead straight to the newly emerging sense of the word. However, many of these pragmatic ,accidents“ could best be repaired by the hearer if he or she hypothesized that the problematic item was in fact used in a new sense. In such cases, the modern reader will be able to interpret the sentence on basis of the modern use of the word, and the only remaining surprise would be how the contemporary reader/hearer would have been able to do the same, given that he did not know as yet where language history would lead.

The present section illustrates pragmatic accidents for fast (German), even, perfino and selbst. In each case, I will briefly specify the older reading of the word, spell out the presuppositions of that older reading, and then show examples from the crucial time of change where these presuppositions were hard or impossible to accommodate. 


\section{4.a fast (German)}

German and English fast go back to a common adverbial root which meant „tightly, fast“ in the sense of both physical attachment as well as mental attachment to a cause. It is used in this sense in the examples in (13) and (14) (all quotes here are taken from the Deutsches Wörterbuch [DW]).

(13) sölh pflicht halt fast

this duty hold fast

(1535 Schwarzenberg 139, 2, from DW 3:1348)

(14) halt fast den pfluog

hold the plough fast / tightly

(1535 Schwarzenberg 140,2, from DW 3: 1348)

Subsequently, the notion of taking a 'good grip' was extended to gradable properties in general. The word became a degree modifier with the meaning of very much. Here, German and English part ways, the English adverb adopting the notion of moving on with 'high speed', as laid out in the classical study by Stern (1931). The German degree use is illustrated in (15) and (16).

(15) dis ler und trost mich fast erquickt

this lesson and consolation revives me very much

(1535 Schwarzenberg 152,2, from DW 3: 1348)

(16) wenn du gleich fast darnach ringest, so erlangestu es doch nicht.

even if you struggle for it hard, you will not attain it

(1534 Luther, Sir. 11,2, from DW 3: 1350)

The use of an adverb which reports that a property $P$ held to a high degree carries the presupposition that $P$ is a gradable property in the first place. Otherwise, the combination fast $P$ will not make any sense.

The DW offers quotations like the following, around the time when the approximative use emerged. The authors of the dictionary clear-sightedly comment that here, the sense of fast was "leaning towards the newer sense "almost"'. Taking a closer look at the respective examples in order to understand why this may be so, we note that they typically fail to combine fast with a gradable property.

(17) weil er fast hundert ierig war he was very much?/ almost? hundred years old (1534 Luther, Röm. 4,19, from DW 3; 1350)

(18) kamen darauff fast um zwo uren (they) arrived there very much?/ almost? at two o'clock /sharp? (c. 1576 Fischart gl. schif 185, from DW 3: 1350) 
(19) Nun war gedachtes Verzeichniß so accurat eingerichtet,

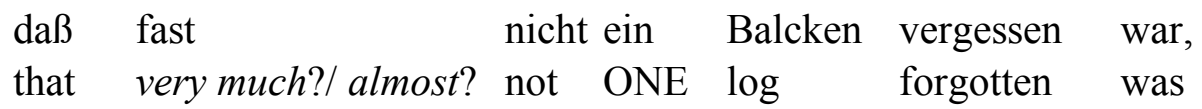
wo er solte eingeschoben, wie er solte bekleidet oder gemahlet, wie er solte behobelt und beschnitzet werden.

(1672, Weise erzn. eingang, from DW 3: 1350)

We will discuss this impression of "leaning towards a newer sense" on basis of an utterance like (17), rendered in the English equivalent in (17').

(17') He was very much $_{\text {deg }} 100$ years old.

Be 100 years old is not usually something that one can be with more or less intensity. Either the speaker was unaware of the problem and erroneously chose fast instead of the qualifier that expresses what he actually had had in mind. Or the speaker indeed conceptualized the property be 100 years old as gradable; perhaps thinking of degrees of senility, or wisdom, or poise. The reader will notice the problem: very much presupposes a gradable property, but be 100 years old isn't one. The required mental search for a way in which be 100 years old could possibly be conceived of as gradable is what makes (17) hard to process: it creates the pragmatic overload for the utterance in (17).

For completeness' sake, note that (17) can not give rise to any implicatures or other inference (general or particular) unless the reader finds some way to map the utterance onto some literal content in the first place, because meaningless utterances don't give rise to implicatures. If this first derivation of literal content should already carry the reader to the proposition 'he was almost 100 years old' then the change from very much to almost does not arise by implicature. In principle, of course, it could be claimed that the reader computed some other proposition $q$ as the literal content of (17) and that this other proposition $q$, in that context, implicated the newer sense 'he was almost 100'. But then, I can't see what $q$ could possibly be.

\section{4.b even}

In its earliest attested stage, once again shared by the German cognate eben, the word even denoted ,evenly, smoothly' as a property of surfaces.

(20) Do past or cleye ther-upon al aboute as ytold bi-fore, caste Scalding hot honey euene ther-upon

Put paste or mud thereon all around as said before cast scalding hot honey evenly thereon

(c. 1450 Horses, p. 113 [Helsinki], quote/translation after Traugott, 2006:346) 
This notion can also be applied in cases where two or more objects put together form an even surface, and hence one fits the other evenly. From such uses, a somewhat later sense developed that can be paraphrased in modern English by: ,exactly, precisely; in (exactly) equal degree'. As to be expected, the exact match can be one between two objects, or an object and a measure, as illustrated in (21) (the passage describes the measures of Noah's ark).

The heght is euen thyrty Cubettys full strenght. ,the height is exactly thirty cubits full strength' (c.1500 Towneley Plays, p. 21 [Helsinki], quote/translation after Traugott, 2006:347)

The qualification that something was ,exactly, just, precisely $P^{\text {“ }}$ presupposes

- a topology of approximating $P$-hood (canonically illustrated by numbers and scales like ,roughly 20 years old' — , exactly 20 years old')

- approximation from more than one direction

The topology need not rest on scientific scales or geometrical spaces; human concepts can rest on more general topological spaces (e.g. Gärdenfors, 2000). The examples in (22) rest on a topology of similarities between singing events, and report closer and loser similarities between events where nightingales are singing and where humans are singing.

She sang approximately like a nightingale She sang exactly like a nightingale

The notion of ,exactness' is inapplicable

- when a property $P$ can not be approximated (\#be roughly/exactly pregnant)

- when a property $P$ is inherently vague itself (\# be roughly/exactly angry)

- when a property $P$ is the polar end of a scale

The last restriction may come somewhat surprisingly, but can easily be verified if we consider infelicitous examples like those in (23). The infelicity arises for all adverbials that express „exactness", and can be reproduced in other languages as well. Hence I take it that the restriction is not one that only accidentally applies to one special adverb of contemporary English alone. It appears to be part of the notion of an exact hit, and its opposite, the missing, that the target point can be missed in more than one direction.
a. \#Tom exactly emptied the glass.
b. \#The dog exactly died.
c. \#Anna read the book exactly to the end.

This was the state of English even at the time when the scalar particle started to develop. The following quotes, taken from Traugott (2001) alone, show attested uses of even around the time of the emergence of the scalar particle. Each of them fails to satisfy one or the other aspect of the topology that is presupposed by the notion of an exact ('even') match. 
(24) whanne I remembre your ffavour and your sadde loffynge delynge to me wardes, ffor south ye make me evene veray glade and joyus in my hart: and on the tothersyde agayn whanne I remembre your yonge youthe. And seeth well that ye be none eater of your mete, the which shuld helpe you greately in waxynge; ffor south than ye make me very hevy again.

,When I remember your beauty and sober loving behaviour toward me, truly you make me really very glad and joyous in my heart, and on the other hand again, when I remember your young age, and see clearly that you are no eater of your food, which should help you greatly in your growing, truly then you make me very sad again'

(1476 Private Letters of John Shillingford, II,7, in Kingsford's Stonor Letters and Papers; translation after Traugott 2001:10)

What we see here is the combination of evene and veray glade (,truly happy'). The latter denotes a gradable property which has vague boundaries. There are no clear criteria from where on a person should count as veray glade in contrast to "simply" glade. Against this background, evene is supposed to contribute some qualification of J.S.'s happiness. The reader will face a conceptual mismatch between the modifier evene and its argument veray glade which violates the topological properties presupposed by evene. The passage is pragmatically problematic if we assume that the author attempted to use a word that means ,precisely'. We could conceptualize the property veray glade as one with clearly circumscribed extension, but it is not clear what should define the exact boundaries of happiness. We therefore face a pragmatic overload. Traugott boldly glosses even as ,really', granting J.S. reasonable (though innovative) use of (Early Modern) English and thus nicely illustrates the move of the charitable hearer. The passage is classed as „must be emphatic“, and indeed, emotional undertones seem to carry away the writer. It is unclear, however, whether we don't just witness a use of the older item even ,exactly' with poorly justified presuppositions. ${ }^{1}$ The following quote of Traugott may show another poorly justified use of ,exactly'.

(25) is not this he that sate and begged? Some sayde: this is he. Other sayd: he is lyke him. But he him selfe sayde: I am even he.

,Is not this the man that sat and begged? Some said: This is he. Others said: He is like him. But he himself said, I am exactly (?) he.'

(1534, Tyndale, New Testament, IX,i. quoted and translated after Traugott 2006: 349)

The protagonists are concerned with the similarity of one person to another. Taking into consideration what the dialogue is actually about, the notion of exactness seems once again poorly in place. To be or not to be identical to someone is, after all, a categorical property and not one that can be approximated: ?Saulus is roughly/ exactly identical to Paulus. What might have interfered is the property of looking similar/exactly like someone. Of course, we can think of visual similarity to ever higher degrees. But that is not what is at stake, the interlocutors do not care whether the speaker is a twin of the man that sate and begged.

\footnotetext{
${ }^{1}$ It is certainly right to assume, as Traugott does, that J.S. may have intended to say „really very happy“, but the words chosen may not have expressed this thought even at the time.
} 
The passage in (26) shows another use of even where the presuppositions of the word in its older sense are violated.

(26) but sayde, he had rather be sycke even vnto death then he wold breake his espousals.

But said he would rather be sick precisely?/ even?/ ø unto death than break his vows.

(1449 Latimer, Sermons: 36; after Traugott 2001: 11)

Once more, the use of even fails to adhere to the presuppositions of approximation. While ,dying' can be approximated by sicknesses of different degrees of severity, it is conceptually impossible to „miss“ dead and die ,roughly“ in contrast to „exactly“. The reader at the time faced the task to accommodate an impossible presupposition, which reads roughly like: „death is not the polar end of the scale of sicknesses of increasing severity" ('exactness' presupposing that the exact hit can be missed in several directions). This quotation will quite naturally lend itself to a reanalysis in the scalar sense that is expressed by modern even.

Note that the range of attested uses of even illustrates that not all the pragmatic ,accidents“ need to receive a rescue interpretation that leads towards the modern sense of the word. In retrospect, all we can say is that those rescue interpretations which led to the hypothesis that even denoted the scalar particle determined the future use of the word. Of course, it can not be proved that the specific passage in (26) (or any other, at that) is the driving pragmatic accident. However, it can plausibly be assumed that the crucial passages looked somewhat like (26).

Let me finally point out, again, that neither (24) nor (25) support the assumption that even in the scalar sense emerged by generalized implicatures (GIIN analysis). In neither (24) nor (25) is even used in its literal old sense plus giving rise to an implicature that exactly $P$ was most surprisingly $P$. The word even is not used reasonably in its old sense at all, and hence can not give rise to implicatures. The reader's hermeneutic activity is initiated by the very observation that the older use of even can not be the one at stake in either example.

\section{4.c perfino}

In its modern sense, perfino translates to English even and can be used in sentences like the one in (27).

$\grave{E}$ venuto perfino Matteo

,even Matteo came' (Visconti 2005:238)

In its traditional sense in Old Italian, perfino literally meant ,through until, to the end'. A typical example, offered in Visconti 2005, is shown in (28).

b. Dentro in un bosco, che'è quivi vicino, / t' imbosca es sta perfino al mattutino. 
,In a wood, which is near here, hide yourself in the wood and stay until morning' (-1380 La Spagna,; after Visconti 2005: 243)

A word that reports that $P$,holds through until the end“ presupposes a topology which defines betweenness and the ancillary notion of an uninterrupted state between two points. The topology can be one in space, but also one on more abstract domains.

The reached point can be neutral (like in (28)) but also conceptualized as a polar endpoint on a scale.

(29) In ciò ancora che perseverò in croce perfino alla morte, ci dà ammaestramento di perfetta obbedienza e pazienza, e di perseverare nella penitenza

,In that too, that he endured the cross until death, he provides us with an example of perfect obedience and patience.'

(1432 Cavalca, Esp. simbolo; after Visconti 2005: 243)

The following quote around the time of emergence of the scalar use 'even' is taken from Visconti (2005). It fails to warrant the presuppositions of perfino in its older sense.

[...] in acqua, in neve, in grandine o pruina: a tutto il ciel s'inclina, perfino a quel che la natura sprezza'

,Water, snow, hail or frost: To everything bends the sky, even to that which nature despises' (1389-1420 S. Serdini, Rime, after Visconti 2005: 244)

The use of perfino in (30) presupposes the existence of a continuum which passes from water, snow, hail and frost to "that which nature despises". Or, is frost the thing that nature despises? And, is there a continuum from good to ever more evil things, or isn't it more a categorical distinction between "the good" and "the bad"? Such questions are indicative for an utterance with a presupposition which may or may not be plausible. In some sense, the speaker in (30) is free to believe in continuous scales of whatever kind (mathematically, there is practically nothing that could stop you from ordering any set whatsoever). But if the scale is too ad hoc, or too private, the hearer will have a hard time in understanding how the speaker believes the presuppositions of (30) satisfied. S/he has hence the choice between guessing and accommodating the speaker's scale (= what the speaker believes hearer will do) and accepting a presupposition failure due to lack of a suitable scale. If the hearer decides for the latter option, s/he will next hypothesize that the speaker actually used perfino in a different sense, and interpret the utterance (30) in a new way-possibly and plausibly assuming that perfino was meant to mean 'even'.

\section{4.d selbst}

Like its English cognate, selbst is attested at an early stage as an intensifier in German. It can still be used in this sense, in the form selbst and its variant selber which unambiguously denotes the intensifier. (31) shows an example. 
Gott selber ruht sich manchmal aus.

God himself takes a rest sometimes.

The intensifier associates with a certain nominal element in the sentence. (31) shows an adnominal use where the intensifier follows the associated element directly. As argued in Baker 1995, Kemmer 1995, the use of selber/selbst presupposes that the associated object (here: ,God') is conceptualized as the center of a salient entourage (here: ,God' as the center of His creation). Generally, the use of intensifying selber only makes sense if the associated referent, the $x$ of $x$-self so to speak, is understood to come with an entourage, peripheral objects or persons, in which $x$ constitutes a central point. I will refer to this presupposition as the entourage presupposition; we will leave the details on focussing and accent placement aside for the ease of exposition.

(32) shows a quotation from 1650, around the time when the scalar use emerged. We can assume that the newer sense selbst $=$ even was not in use at the time when this passage was written. I offer the full context, but the crucial part is the underlined sentence at the end.

$$
\begin{aligned}
& \text { Man kan / es ist nicht ohn / ein blut begierig Thier } \\
& \text { Gewöhnen daß es spiel vnd nieder knie vor dir / } \\
& \text { Man kan / waß noch viel mehr / die starcke flut vmbkehren. } \\
& \text { Den strömen widerstehn / den tollen wellen wehren. } \\
& \text { Man dämpfft der flammen macht / man segelt gegen wind / } \\
& \text { Man stürtz't die felsen hin wo thäl vnd hölen sind. }
\end{aligned}
$$

'One can, it's not easy, a bloodthirsty animal / train so that it will play and kneel down before you / One can, which is even more, reverse the strong flood / resist the streams, restrain the wild waves / One damps the mighty flames, one sails against the winds / One throws boulders where there are valleys and caverns'

Man kan die steine selbst mit weitzen überziehen.
one can the stones 'selbst' with wheat cover
'One can cover the stones 'selbst' (themselves/even?) with wheat'
(1650 Leo Arm., II,5)

In a traditional interpretation of the passage on basis of the intensifier, the reader ends with the following ingredients for the eventual meaning of the underlined sentence:

selbst $=$ intensifier, is supposed to associate with

Steine, stones' to yield 'stones themselves'

presupposition: ,stones' are something that has an entourage, that is the natural center of some ontological domain.

Once again, this presupposition is not logically contradictory but still hard to satisfy or fill with content. What could be the entourage of stones? Mentioned in the text are blutbegierig Thier 
,bloodthirsty animal', starcke flut ,flood', tolle wellen , wild waves', flammen ,flames' — but ,stones' are not a plausible center in this entourage of things either today or in 1650. To check this, consider the following statement:

Bloodthirsty animals, high flood, wild waves, flames: yet, stones are the worst of them all.

This assertion is as implausible today as it must have been implausible in 1650. Once again, the reader will face a pragmatic overload when s/he tries to work out an appropriate way to accommodate the presuppositions of (32) under the old reading of selbst. Once again, this may be reason for the reader to wonder whether the speaker intended to use selbst in a new sense, one that would not give rise to un-accommodatable presuppositions.

We have now seen several instances utterances with pragmatic overload, caused by items that soon after adopted a new meaning. In the next section, I will discuss in more detail why the repair strategies for the quoted examples could indeed lead the reader/hearer to assume that the word was used in a new sense, and that it was plausibly the sense that we find in permanent use some decades later. Before moving on, let me mention that another nice instance of presupposition failures in the pre-change phase can be traced in the development of lauter, see Eckardt 2006: chap.7.

What is most striking about such observations, however, is that pragmatic accidents of this kind clearly are not restricted to language use in ancient times. Instances of pragmatic overload can be observed on a daily basis as soon as you start watching the utterances in your daily environment. It is tempting to think that repair interpretations can in some cases converge on recognizable new stages in the use of words.

\section{APO, AND THE CHARITABLE HEARER}

The examples in section 4 illustrate how an utterance can create a pragmatic overload: The utterance under a conservative interpretation will trigger presuppositions that the hearer can not easily accommodate or refute. The hearer has three options: S/he can (a) be uncharitable and refuse to interpret the utterance at all, or (b) face the pragmatic overload and attempt to reconceptualize the world such that the presupposition makes sense and is consistent, or (c) hypothesize a new meaning for parts of the utterance, notably the item that gave rise to the problematic presupposition. Option (c) will allow the hearer to Avoid the Pragmatic Overload. In the examples at hand, it makes indeed sense to believe that (c) is a viable option for the reader. The hypothesized interpretations for fast, even, perfino, and selbst which a posteriori turned out to be adopted as new meanings into the lexicon will fit the context better than the conservative senses, and deviate from the older senses in only minimal ways. We will take a look at each case in turn. 
fast: Combining fast old $_{\text {w }}$ with a non-gradable property $P$ creates the problem that the degree modifier can not contribute semantically. The repair strategy was to look for a superproperty $\Pi$ of $P$ which in turn is gradable, and where $P$ is the polar end point. (In the case of being 100 years old, the scale of lower ages offers itself, for example.) The semantic contribution of fast was then taken to be relative to this gradable superproperty: The subject has a property which ranks high on the $\prod$ scale. (E.g. the subject has an age that ranks high on the $0-100$ year scale; in other words, he is almost 100 years old.)

very much 100 years old $>$ almost 100 years old

Interestingly, the semantic contribution of fast $t_{\text {new }}$ remains the same as for fast old $_{\text {, but }}$ the presupposed background has changed drastically. The following figures visualize the change.
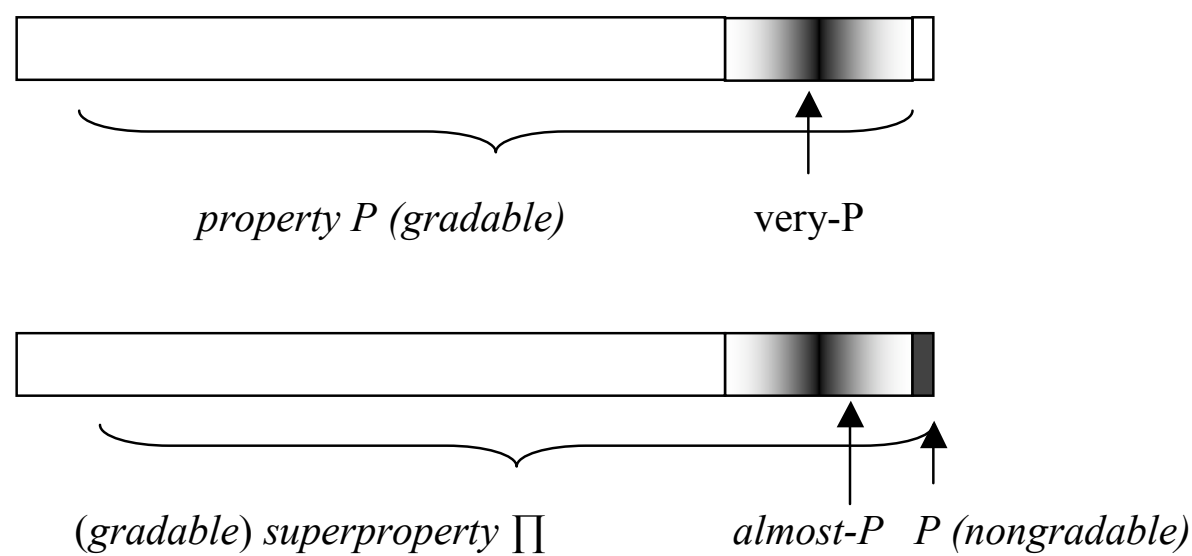

The change implements the idea that

$$
\text { very } \Pi=\text { almost } P
$$

Eckardt (2007) and similarly Penka (2006), offer a full semantic spell out of this idea. The

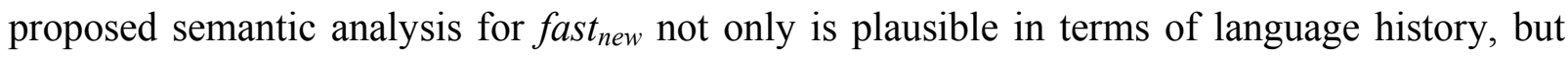
moreover covers all possible uses that we witness in modern German and constitutes an improvement on earlier analyses that essentially rest on Sadock (1981). In view of the appealing simplicity of the reanalysis in question, it becomes all the more implausible to believe that the semantic change occurred on the basis of some hitherto undetected kind of use where fast/very much could give rise to implicatures in the sense of fast /almost.

even: In the case of even, the adjustment in the mental lexicon was again minimal. As discussed above, even in its older sense , precisely' will have required-like all other adverbs that express the notion of an exact hit or match - that the state of affair $Q$ in question is part of a topology of more or less similar states of affairs surrounding it. Importantly, the notion of 
,exactness' prohibits topologies where $Q$ is the polar end point of a linear topological space. ${ }^{2}$ This prohibition was violated in examples like (26), repeated in a modern gloss in (38).

\section{exactly fatally sick}

The hearer accepted that $e^{2} e_{\text {old }}$ was used in a situation where it applied to a polar end point. It would, however, be void to adopt a word that lexifies what is obvious from the content of the rest of the sentence. The underlined part would explicate the semantic contribution: The subject could be sick to death, and this is as far as you can get. Hence, the hearer hypothesized that the scales in question correlated with a more subjective scale of the speaker, e.g. one of increased surprise, decreased probability, (here) increased woe, etc. These subjective scales formed the backbone of modern even in the sense exemplified in (39).

\section{sick even to death}

Two points may be worth mentioning. First, these interpretive efforts on the hearer's side might often be at the basis of subjectification in the sense of Traugott (1995). The hearer, confronted with (38), has to make a guess what the speaker might have wanted to express. In many cases, there are canonical answers to this question. At least in the cases at hand, we do not face a speaker-driven process. Uttering incoherent sentences and hoping that the hearer will grab your message does not seem a rational communicative strategy. ${ }^{3}$ Second, the shift that leads from (38) to (39) can not be described as implicatures of an interpretation of (38) on the basis of even in its older sense. Nor can I think of any uses of even 'exactly' that create an implicature 'even', an implicature that could then be reanalysed as literal meaning (GIIN). ${ }^{4}$ The pragmatic overload view on change, in contrast, can offer a plausible analysis for attested examples rather than speculating on the existence of unconceivable unattested cases.

perfino: The shift of perfino concerns once more the kinds of scales that can be referred to. Traditionally, perfino was restricted to scales in the world, as was shown in Visconti (2005). The pragmatic accident happened in cases where the hearer could not make out any reasonable conceptual scales. In (30) above, the writer lists a number of evils but does not suggest that they are linearly ordered in any way. I repeat the example in the English version, volitionally inserting the translation of the older sense of perfino. This is the semantic material for the (earlier Italian) reader to start with.

$$
\text { the sky bends "through until" to that which nature despises }
$$

\footnotetext{
${ }^{2}$ A topology, in mathematical terms, is a space with a measure function that measures the distance between any two points in the space. See Gärdenfors (2000) for a general theory of concepts in topological spaces.

${ }^{3}$ Notwithstanding that of course, incoherent linguistic behaviour and emotional stress often go hand in hand. But incoherence in such situations is rather taken as a metalinguistic signal by the observer, usually.

${ }^{4}$ This does not, of course, mean that such uses do not exist. Maybe it's just that I am not trying hard enough. Yet, I have not so far encountered any plausible fictuous example where any sentence with a word that means, exactly' would implicate the analogous proposition with ,even' replacing , exactly'.
} 
The underlined part presupposes a scale. Lacking a more contentful continuous scale, the reader can meet the need for a scale by interpreting the sentence against the all-purpose scale of increased surprise / decreasing probability. The reader will hence understand that the proposition 'the sky bends to that which nature despises' is presented as the endpoint on that scale. Particles that signal this kind of side information are those that correspond to 'even'. Hence, (40) with the surprise scale is synonymous to (41).

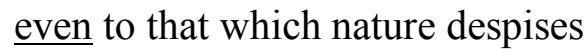

selbst: In the turning point examples of selbst, the hearer/reader was faced with the task to reconstruct a core-periphery structure that is presupposed by intensifiers (-self). As shown in the above quotation, it may not have been inconsistent, but simply implausible to adopt such a core-periphery for the examples at hand. (42) would require us to think about stones as the core instance of nonfertile ground (true) after a long passage that did not have to do with fertility in the least, but rather with various kinds of attempts to fight hostile natural forces.

\section{grow wheat on [stones themselves]}

In such situations, the reader may have refused to face the pragmatic overload and instead searched for a simpler interpretation of the sentence. While it is conceptually hard to switch from tempests, floods and flames to soils of different quality, it is quite easy in the given context to understand the tasks as ordered to be more and more unfeasible. The task that can least likely be performed is the task marked by selbst. This hypothesized semantic analysis will have several consequences. The new item selbst $t_{\text {new }}$ can take sentence scope, it no longer is in focus (unlike in the older construction; see Eckardt, 2001), focussing may be used to indicate the kind of alternatives on the scale, and selbst $t_{\text {new }}$ indicates that the reported state of affairs is high on that scale. The resulting reanalysis is the one in (43).

even $[\text { grow wheat on stones }]_{\mathrm{F}}$

In the present overview, I omit the details of the meaning shifts at stake (see earlier work for detailed semantic analyses). Case studies reveal that hearers are surprisingly conservative, maintaining as much of earlier semantic structure as possible and making new content fit. The present examples suggest that the concept of scale is important in human thinking both as a new player in meaning (even, selbst, perfino) as well as a semantic part to be maintained (fast).

Let me sum up some characteristics of language changes that arise in the attempt to avoid pragmatic overload. ${ }^{5}$ Firstly, they constitute instantaneous changes of language in the hearer's competence, resulting from the attempt to interpret one specific utterance. Whatever gradual

\footnotetext{
${ }^{5} \mathrm{I}$ am not claiming that all language change is instantaneous, that all language change is initiated by the APO principle, that all language changes of a certain class — e.g. grammaticalization — are initiated by APO. The more modest claim is simply that instantaneous change does exist. It does not rest on stupid or creative speakers. It does not, in all likelihood, leave an impression of novelty in the hearer. It is part of perfectly normal ordinary use of language (Hermann Paul).
} 
spreads may occur afterwards - the hearer gradually gaining faith in a new sense of a word, his surroundings being gradually infected to share this new item-the initial shift is discrete. The competence of the speaker may be momentarily weak, but all in all we face competent speakers without attempts at creativity. The witnessed lapses of tongue or pen are not beyond what we see daily in our own environment, interacting with speakers that we hold fully competent. The competence of the hearer likewise need not be doubted. (In some sense, $\mathrm{s} / \mathrm{he}$ is still the more competent of the two.) The reanalyses do not fit under the label of „misunderstandings“ of the kind prevalent in other domains of language change, for instance contact phenomena or L2 speaker errors.

From a more general perspective, the trend to avoid pragmatic overload bears resemblance to similar trends towards simplicity and clarity that have been postulated in syntax, specifically in language acquisition and language change. Lightfoot (1979) is a classical reference. Lightfoot attempted to explain the development of the modal system in English by, among other factors, the dismissal of more complex structures in favour of simpler options. Lightfoot's ,avoid complex syntactic structure" principle in 1979 can be seen as the syntactic twin principle to „avoid pragmatic overload“ on the semantic/pragmatic side. Even though Lightfoot reshaped his ideas about the development of the modals in later years, the idea that simpler syntactic structures replace more complex structures in developmental processes has been retained (e.g. Lightfoot, 1991, 1999).

The Avoid Pragmatic Overload analysis is moreover appealing in that it fully adheres to the uniformitarian principle. The uniformitarian principle in language history states, roughly, that any analysis of language change should rest on processes that can still be observed in contemporary language use. The APO analysis fulfils this requirement. The proposed changes rest on communicative situations that we frequently witness ourselves. What is still unexplored is a quantitative analysis of this type of change. How many pragmatic accidents are necessary for change to become likely? What is the ratio of accidents in total to accidents where reanalysis led to the item that was later adopted into the lexicon? So far, these questions can only receive an impressionistic answer, as traditional classifications tend to sort quotes of words by sense, not by more general categories like whether they create pragmatic overload.

Many studies report that the point where a new item emerges is frequently preceded by a phase of great variability in the use of the crucial word. We might understand these pre-phases as times where a word was promoted by sociolinguistic factors (,fashion words") or where other priming effects led to more retrievals of the word than what would have been warranted. The modest aim of this paper has been, to offer a new way in which we might understand what really happens, linguistically, in some of the more puzzling ones of such variable uses at the turning point between an older and an emerging new word sense. The appeal of this analysis consists in that it addresses the attested quotes themselves. The attested quotes are perceived as possible source of change. The quotes are not classed as clear instances of the new language use, "made possible by changes that we see nowhere in the data". In that sense, the present approach adheres to my slogan in section 1: it is one more attempt to understand language change without mysteries. 


\section{REFERENCES}

Baker, C. L. (1995), „Contrast, Discourse Prominence, and Intensification, with Special Reference to Locally free Reflexives in British English.“ Language 71, pp. 63 - 102.

Grimm, J. and Grimm, W. (Eds.) (1854-1960), Deutsches Wörterbuch. S. Hirzel, Leipzig. Quellenverzeichnis 1971.

Eckardt, R. (2001), "Reanalysing 'selbst””. Natural Language Semantics 9, pp. 371-412.

Eckardt, R. (2006), Meaning Change in Grammaticalization. An enquiry into semantic reanalysis. Oxford University Press, Oxford.

Eckardt, R. (2007), Almost — A Theory. Ms, University of Göttingen and Semantics Archive.

Gabelentz, G. von der (1891), Die Sprachwissenschaft. Ihre Aufgaben, Methoden, und bisherigen Ergebnisse. Weigel, Leipzig.

Gärdenfors, P. (2000), Conceptual spaces: The geometry of thought. MIT Press, Cambridge MA.

Geurts, B. (1999), Presuppositions and Pronouns. Elsevier, Oxford.

Hansen, M.-B. M. and J. Visconti (2005), The evolution of pragmatic markers: Introduction. Journal of Historical Pragmatics 6:2, pp. 177-187.

Kemmer, S. (1995), "Emphatic and reflexive -self: Expectations, viewpoint, and subjectivity." Stein, D. and Wright, S. (Eds.), Subjectivity and Subjectivism. Cambridge University Press, Cambridge. pp. $55-82$.

König, E. and Traugott, E. C. (1988), "Pragmatic strengthening and semantic change: the conventionalizing of conversational implicature.” Hüllen, W. and Schulze, R. (Eds.), Understanding the Lexicon: Meaning, Sense and World Knowledge in Lexical Semantics, Niemeyer, Tübingen, pp. 110-24.

Lightfoot, D. (1979), Principles of Diachronic Syntax. Cambridge University Press, Cambridge.

Lightfoot, D. (1991), How to set parameters: Arguments from language change. MIT Press, Cambridge, MA.

Lightfoot, D. (1999), The development of language: Acquisition, change and evolution. Blackwell, Oxford.

Paul, H. (1920), Prinzipien der Sprachgeschichte. Niemeyer, $5^{\text {th }}$ edition, Halle.

Penka, D. (2006), “Almost there: The Meaning of almost.“ Ebert, C. and Endriss C. (Eds.). Proceedings of Sinn und Bedeutung 10. ZAS Papers in Linguistics, Nr. 44, Berlin. pp. 275-286.

Sadock, J. M. (1981), “Almost”” in: Cole, P. (Ed.), Radical Pragmatics. Academic Press, New York: pp. 257-271.

Stalnaker, R. (2002), "Common Ground", Linguistics and Philosophy 25, pp. $701-721$.

Stern, G. (1968 [1931]), Meaning and Change of Meaning. Indiana University Press, Indiana. 
Traugott, E. C. (1988), "Pragmatic strengthening and grammaticalization", Axmaker, S., Jaisser, A. and Singmaster, H. (Eds.), Proceedings of the 14th Annual Meeting of the Berkeley Linguistic Society. Berkeley Linguistic Society, Berkeley, pp. 406-16.

Traugott, E. C. (1995), "Subjectification in Grammaticalization", D. Stein, S. Wright (Eds.), Subjectivity and Subjectification. Cambridge University Press, Cambridge, pp. 31 54.

Traugott, E. C. (2001), “How do scalar meanings arise?” LSA Institute Collitz Lecture, July 18 th, 2001.

Traugott, E. C. (2006), "The semantic development of scalar focus particles", van Kemenade, A. and Los, B. (Eds.), The Handbook of the History of English, Blackwell, London, pp. 335-359.

Traugott, E. C., and R. B. Dasher (2002), Regularity in Semantic Change, Cambridge University Press, Cambridge.

Visconti, J. (2005), "On the origins of scalar particles in Italian", Journal of Historical Pragmatics 6:2, 237-261.

\section{Historical sources}

[Fischart gl. schif] Fischart, Johann. 1576. Das glückhafft schif von Zürich. Nachrduck in Johann Fischart: Geschichtklitterung (Gargantua). Düsseldorf 1963.

[Leo Arm.] Andreas Gryphius. 1560. Armenius: Trauerspiel von Andreas Gryphius. Ed. Peter Rusterholz. Leipzig, Reclam, 1971.

[Luther, Sir.] Martin Luther. 1534. Biblia. Jesus Sirach. Complete facsimile edition, Köln, Taschen, 2002.

[Luther, Röm.] Martin Luther. 1534. Biblia. Brief an die Römer. Complete facsimile edition, Köln, Taschen, 2002.

[Schwarzenberg] Schwarzenberg, Joh. 1535. Von, gebührliche werk. verdeutschung von Cicero de Officiis.

[Weise erzn]: Weise, Christian. 15 Die drey ärgsten Ertz-Narren in der gantzen Welt. 1672.

Nachdruck in Christian Weise: Sämtliche Werke. Berlin und New York 1971. 